\title{
A Population Based Study on the Association of Thyroid Status with Components of the Metabolic Syndrome
}

\section{Fahimeh Ramezani Tehrani ${ }^{1 *}$, Maryam Tohidi ${ }^{2}$, Marzieh Rostami Dovom ${ }^{1}$ and Fereidoun Azizi ${ }^{3}$}

${ }^{1}$ Reproductive Endocrinology Research Center, Shahid Beheshti University of Medical Sciences, Tehran, Iran ${ }^{2}$ Prevention of Metabolic Disorders Research Center, Iran

${ }^{3}$ Endocrine research center, Iran

\begin{abstract}
Introduction: Although overt hypothyroidism is a known risk factor for cardiovascular disease, there is no consensus regarding the impact of subclinical hypothyroidism $(\mathrm{SCH})$ on metabolic syndrome (MetS). A positive association between overt hypothyroidism and hypercholesterolemia is well documented. This study investigated whether there is any association between $(\mathrm{SCH})$ and MetS components.
\end{abstract}

Material and Methods: In a community based population using the stratified, multistage probability cluster sampling method, 1126 women aged 18-45 years, were randomly selected from four urban areas of Iran. After considering the exclusion criteria, 914 subjects were enrolled. Multiple logistic regression analysis was used to investigate the simultaneous effect of different variables on MetS and each of its components.

Results: In this study the prevalence of euthyroid women with MetS was $16.9 \%$, which was similar to its prevalence among women with SCH (19.2\%). The average estimated total score of Mets in women with SCH was significantly higher than the euthyroid women $(p=0.006)$. We found that TSH levels in $\mathrm{SCH}$ subjects were negatively and positively correlated with HDL-C and diastolic blood pressure respectively, even after adjustment for age, BMI and HOMA-IR. There was no significant correlation between TSH level in SCH subjects and other MetS components. The prevalence of obesity/overweight in women with $\mathrm{SCH}$ was higher than that in euthyroid women.

Discussion: Although there is no evidence of any association between thyroid status and all Mets components, but thyroid dysfunction can be considered a risk factor for metabolic syndrome.

Abbreviations: SCH- Sub Clinical Hypothyroidism; MetSMetabolic Syndrome

\section{Introduction}

Metabolic syndrome (Mets), a complex of disorders including the abdominal obesity, dyslipidemia, hypertension and impaired fasting glucose, is one of the known risk factors for cardiovascular disease (CVD) [1-3]. Despite the controversy on its definition it is estimated that one out of four people around the world suffers from this syndrome $[4,5]$. The prevalence of Mets in Iran is reported to be $30.1 \%$, using the ATP III definition [6].

Overt hypothyroidism acts as a CVD risk factor through several mechanisms, as a result of which the incidence of heart attack can increase over two fold in hypothyroid subjects [7-11]. A positive association between overt hypothyroidism and hypercholesterolemia is well recognized [12]. In addition it is reported that thyroid hormones influence vascular smooth muscles, consequently reducing arterial resistance, and causing a decline in diastolic blood pressure[13]. Moreover, insulin sensitivity can be affected by thyroid function and a positive association between overt hypothyroidism and BMI has been well documented [14,15] .

The correlation between subclinical hypothyroidism $(\mathrm{SCH})$ and Mets and its components varies in different studies and seems to be influenced by age, gender and race of study participants[9,10,16]. A significant correlation between $\mathrm{SCH}$ and Mets was reported in a study from India [17]. Park et al. found that the serum concentration of TSH in menopausal women with $\mathrm{SCH}$ was a powerful predictor of Mets and its components [18]. However in contrast to these studies, the prevalence of Mets among Turkish subjects with subclinical thyroid disorders was similar to normal subjects ( $0.35 \%$ compared with $0.33 \%)$ [19]; in the Manji et al. study there was no significant association between BMI and serum TSH levels in subjects with no apparent impairment of thyroid function [20].

We aimed to investigate whether there was any association between $\mathrm{SCH}$ with Mets or its components in a community based population of Iranian reproductive aged women.

\section{Material and Methods}

Using the stratified, multistage probability cluster sampling method, a total of 1126 women, aged $18-45 \mathrm{y}$, were recruited from among reproductive aged women, living in urban areas of four randomly selected provinces of different geographic regions of Iran, i.e. Ghazvin (Central), Kermanshah(East), Golestan (North) and Hormozgan (South). The Iranian household list available from the Health Department was used to identify the frame for the selection of the sampling units.

*Corresponding author: Prof. Fahimeh Ramezani Tehrani M, Reproductive Endocrinology Research Center, Research Institute for Endocrine Sciences, Shahid Beheshti University of Medical Sciences, Parvaneh, Yaman Street Velenjak, P.O.Box:19395-4763, Tehran, I.R.Iran, Postal Code: 1985717413, Tel: 98-21-22409309; Fax: 98-21-22402463; E-mail: ramezani@endocrine. ac.ir, framezan@post.harvard.edu

Received July 20, 2011; Accepted November 18, 2011; Published November 22, 2011

Citation: Tehrani FR, Tohidi M, Dovom MR, Azizi F (2011) A Population Based Study on the Association of Thyroid Status with Components of the Metabolic Syndrome. J Diabetes Metab 2:156. doi:10.4172/2155-6156.1000156

Copyright: (c) 2011 Tehrani FR, et al. This is an open-access article distributed under the terms of the Creative Commons Attribution License, which permits unrestricted use, distribution, and reproduction in any medium, provided the original author and source are credited. 
Before data collection, trained interviewers explained in detail the purpose and procedure of the study to subjects at their homes and obtained their written consent, following which a questionnaire including demographic and reproductive histories, family history and a personal history of thyroid diseases, diabetes, hypertension and dyslipidemia and their treatment was completed. All participants underwent clinical examinations, where body weight, height, waist (WC), hip circumferences (HC) and blood pressure were measured. Weight was measured to the nearest $0.1 \mathrm{~kg}$ on a calibrated beam scale. Height and waist circumference (WC) were measured to the nearest $0.5 \mathrm{~cm}$ with a measuring tape. Waist was measured midway between the lower rib margin and the iliac-crest at the end of a gentle expiration. Body mass index was calculated as weight in kilograms divided by the height in meters squared $\left(\mathrm{kg} / \mathrm{m}^{2}\right)$. Blood pressure was measured twice, with a 3-min interval, after 30 minutes of rest and the mean value of the two measurements was used. An overnight fasting venous blood sample was obtained from each subject and stored at $-80^{\circ} \mathrm{C}$, until the time of measurements.

Menopausal women, those who had undergone hysterectomy or bilateral oophorectomy, participants having a personal history of thyroid disease and had been taking thyroxin or anti-thyroid drugs for treatment, those taking medication affecting thyroid function, and any pregnant or lactating women were excluded $(n=105)$. Furthermore women with incomplete clinical information or those whose blood samples were not available $(n=107)$ were also excluded from the present study.

Fasting serum glucose, triglycerides (TG), total cholesterol (TC) and high-density lipoprotein cholesterol (HDL-C) were measured using the enzymatic colorimetric method (Pars Azmon Inc., Tehran, Iran) using a Selectra 2 auto-analyzer (Vital Scientific, Spankeren, The Netherlands). The Friedewald equation was used to calculate lowdensity lipoprotein cholesterol (LDL- C); samples with TG $>400 \mathrm{mg} / \mathrm{dl}$ were assayed by the direct method. In all the biochemical analyses, the intra- and inter-assay coefficients of variation (CV) were less than $2.5 \%$ and $3.2 \%$ respectively.

Free thyroxin (FT4) was measured by radioimmunoassay and the thyroid- stimulating hormone (TSH) was assayed by immuneradiometric assay (Izotop, Budapest, Hungary) with a Wallac Wizard gamma counter (Turku, Finland).); the intra- and inter-assay CVs were $3.4 \%$ and $4.6 \%$ for FT4 and $1.7 \%$ and $3.4 \%$ for respectively TSH determinations.

We measured insulin by immune-enzymometric assay using commercial kits (Mercodia, Upssala, Sweden and the Sunrise ELISA reader (Tecan Co., Salzburg, Austria), the intra- and inter-assay CV being 2.4 and 5.8\%, respectively. HOMA-IR was calculated according to the formula: HOMA-IR $=[($ Fasting insulin level $(\mathrm{mU} / \mathrm{L}) \times$ Fasting plasma glucose $(\mathrm{mmol} / \mathrm{L})] / 22.5$.

\section{Definitions}

$\mathrm{SCH}(\mathrm{SCH})$ is defined as serum free T4 level within the reference range in the presence of elevated serum TSH level (4.5mIU/l).

We used the definition of the NCEP ATPIII modified in 2005 by the American Heart Association (AHA) and the national Heart, Lung, and Blood Institute [21]. We adjusted the waist circumference cut off value, $91.5 \mathrm{~cm}$, as it suggested for Iranian women [22]. According to this definition, Metabolic Syndrome was suggested as the following criteria : the presence of any three of five risk factors of the following: (1) Abdominal obesity as WC $\geq 91.5 \mathrm{~cm}$ for women (2) FPG $\geq 100 \mathrm{mg} /$ dl or drug treatment; (3) Fasting TG $\geq 150 \mathrm{mg} / \mathrm{dl}$ or drug treatment; (4) Fasting HDL-C $<50 \mathrm{mg} / \mathrm{dl}$ in women or drug treatment; (5) Raised blood pressure defined as systolic blood pressure (SBP) $\geq 130 \mathrm{mmHg}$, diastolic blood pressure (DBP) $\geq 85 \mathrm{mmHg}$ or antihypertensive drug treatment or antihypertensive drug treatment.

For each MetS criteria we considered 1 point for any woman who had the criteria; the individual MetS risk score was calculated by sum of points that were gained from the 5 MetS criteria.

\section{Statistical analysis}

Continuous variables were checked for normality using the one-sample Kolmogorov-Smirnov test; they are expressed as mean \pm standard deviation and/or median and inter quartile ranges, as appropriate. The categorical variables are expressed as percentages. Two-sample comparisons were used by Fisher's exact test, Student's t test, or Mann-Whitney U test, as appropriate. Multiple linear regression analysis was performed to identify relationships between serum lipid parameters, systolic and diastolic blood pressure as dependent variables and thyroid function after adjusting for BMI, age and HOMA-IR. Multiple logistic regression analysis using the enter procedure was performed to investigate the simultaneous effect of different variables on Mets and each of its components. The interactions between all of covariates included in the final models were tested. Data analysis was performed using the SPSS 15.0 PC package (SPSS Inc., Chicago, IL).

\section{Results}

Of the 1126 women, aged $18-45$, recruited for the present study, 914 subjects met our inclusion criteria; of these 720 participants (78.8\%) were euthyroid and 194 women $(21.2 \%)$ had sub-clinical hypothyroidism.

Clinical characteristics, anthropometric and biochemical parameters of participants with $\mathrm{SCH}$ in comparison to those with normal thyroid function are summarized in Table 1 . There was a significant difference between the means of body mass index (BMI), age, systolic and diastolic blood pressure, waist circumference and HDL serum levels of women with SCH in comparison to these values in euthyroid women. There was no significant difference between serum insulin and HOMA-IR in hypothyroid women compared to their euthyroid counterparts. Of the 914 women participants, 159 (17.5\%) had Mets, among these women, $11.3 \%$ had three, $5.1 \%$ had four and only $1 \%$ had all of the five components of Mets. The prevalence of Mets among hypothyroid women was $19 \%$, and of these, $10.3 \%, 8.2 \%$ and $0.5 \%$ had three, four and five criteria of Mets. Prevalence of Mets in subjects with normal thyroid function was $16.9 \% ; 11.4 \%$ had three components $4.3 \%$ had four and $1.1 \%$ had five Mets criteria.

After adjustment for BMI there were no statistically significant associations between TSH and total cholesterol, LDL or FBS, but there was a significant negative association between TSH and HDL $(p=0.001$, $\mathrm{r}=-0.115)$ and between TSH and diastolic blood pressure $(\mathrm{p}=0.001, \mathrm{r}=$ 0.001). Table 2 demonstrates the predictive coefficient (standardized beta) of Mets before and after further adjustment for other variables. There was a positive, statistically significant correlation between serum cholesterol and TSH levels (Standardized $\mathrm{B}=0.001, \mathrm{p}=0.02$ ) but it ceased to exist after further adjustment for age, BMI and HOMA-IR, in spite of mild increase in its standardized beta. Multivariate logistic regression analysis revealed that increasing TSH levels were associated with an increase in diastolic blood pressure and decrease in HDL-C. 
Citation: Tehrani FR, Tohidi M, Dovom MR, Azizi F (2011) A Population Based Study on the Association of Thyroid Status with Components of the Metabolic Syndrome. J Diabetes Metab 2:156. doi:10.4172/2155-6156.1000156

Page 3 of 6

\begin{tabular}{|c|c|c|c|}
\hline & Euthyroid $\mathrm{N}=720$ & $\mathrm{SCH} \mathrm{N}=194$ & $P$ value \\
\hline Age & $34 \pm 7.6 \dagger$ & $35.8 \pm 7.4 \dagger$ & 0.003 \\
\hline $\begin{array}{l}\text { Obesity } \\
\text { Waist(cm) } \\
\text { BMI(Kg/M2) } \\
\text { Abdominal obesity Prevalence (\%) } \\
\text { BMl>30( Kg/M2) }\end{array}$ & $\begin{array}{l}84.5 \pm 12.2 \dagger \\
26.9 \pm 5.1 \dagger \\
20.7 \\
23.1\end{array}$ & $\begin{array}{l}86.9 \pm 12 \dagger \\
27.9 \pm 5.1 \dagger \\
26.3 \\
28.9\end{array}$ & $\begin{array}{l}0.01 \\
0.002 \\
0.05 \\
0.06\end{array}$ \\
\hline $\begin{array}{l}\text { High blood Pressure } \\
\text { Systolic }(\mathrm{mmHg}) \\
\text { diastolic(mmHg) } \\
\text { High blood pressure prevalence (\%) } \\
\text { HBP treatment prevalence }(\%) \\
\text { BP>130/85 prevalence }(\%)\end{array}$ & $\begin{array}{l}109 \pm 13.9 \dagger \\
69.3 \pm 11 \dagger \\
2.1 \\
2.8 \\
5.3\end{array}$ & $\begin{array}{l}111.2 \pm 14.1 \dagger \\
71.1 \pm 11 \dagger \\
3.6 \\
3.61 \\
7.61\end{array}$ & $\begin{array}{l}0.012 \\
0.008 \\
\text { NS } \\
\text { NS } \\
\text { NS }\end{array}$ \\
\hline $\begin{array}{l}\text { Blood Lipid } \\
\text { Total cholesterol(mg/dl) } \\
\text { TG }(\mathrm{mg} / \mathrm{dl}) \\
\text { LDL cholesterol(mg/dl) } \\
\text { HDL cholesterol(mg/dl) } \\
\text { Chl } \geq 150 \mathrm{mg} / \mathrm{dl}(\%) \\
\text { Chl } \leq 50 \mathrm{mg} / \mathrm{dl}(\%) \\
\text { TG } \geq 150 \mathrm{mg} / \mathrm{dl}(\%)\end{array}$ & $\begin{array}{l}184.8 \pm 41.7 \dagger \\
140.2 \pm 97.7 \dagger \\
111.2 \pm 35.8 \dagger \\
45.7 \pm 13.2 \dagger \\
80.6 \\
64.1 \\
30.5\end{array}$ & $\begin{array}{l}185 \pm 38.2 \dagger \\
148.8 \pm 100.1 \dagger \\
111.6 \pm 33.9 \dagger \\
43.9 \pm 12 \dagger \\
85 \\
71 \\
40.4\end{array}$ & $\begin{array}{l}\text { NS } \\
\text { NS } \\
\text { NS } \\
0.01 \\
\text { NS } \\
0.04 \\
0.006\end{array}$ \\
\hline $\begin{array}{l}\text { Blood sugar } \\
\text { FBS(mg/dl) } \\
\text { Insulin } \\
\text { HOMA-IR } \\
\text { Diabetic Mellitus (\%) } \\
\text { FBS>100mg/dl (\%) } \\
\text { Metabolic Syndrome } \\
\text { Metabolic syndrome score } \\
\text { Metabolic Syndrome prevalence (\%) }\end{array}$ & $\begin{array}{l}85.9 \pm 27.2 \dagger \\
9.2 \pm 9.9 \dagger \\
2.2 \pm 3.1 \dagger \\
4.6 \\
17.6 \\
76.6 \\
1.3 \pm 1.6 \dagger \\
16.9\end{array}$ & $\begin{array}{l}89.3 \pm 21.7 \dagger \\
8.2 \pm 5.4 \dagger \\
1.9 \pm 1.8 \dagger \\
5.2 \\
16.6 \\
23.4 \\
1.6 \pm 1.2 \dagger \\
19.2\end{array}$ & $\begin{array}{l}\text { NS } \\
\text { NS } \\
\text { NS } \\
\text { NS } \\
\text { NS } \\
\text { NS } \\
0.013 \\
\text { NS }\end{array}$ \\
\hline
\end{tabular}

$\mathrm{SCH}$ : Women with subclinical hypothyroidism; † mean $\pm \mathrm{SD}$

Table 1: The basic and metabolic characteristics of study subjects according to the thyroid status.

\begin{tabular}{|c|c|c|c|c|c|c|c|}
\hline & Model & & TSH & & & Free T4 & \\
\hline & & $\beta$ & $P$ value* & $\mathrm{R}^{2}$ & $\beta$ & $P$ value & $\mathrm{R}^{2}$ \\
\hline Total Cholesterol & $\begin{array}{l}1 \\
2 \\
3 \\
4\end{array}$ & $\begin{array}{l}0.001 \\
-0.031 \\
-0.032 \\
-0.028\end{array}$ & $\begin{array}{l}{ }^{*} 0.025 \\
0.339 \\
0.315 \\
{ }^{*} 0.0371\end{array}$ & $\begin{array}{l}0.001 \\
0.065 \\
0.099 \\
0.109\end{array}$ & $\begin{array}{l}0.126 \\
0.161 \\
0.156 \\
0.153\end{array}$ & $\begin{array}{l}- \\
- \\
- \\
-\end{array}$ & $\begin{array}{l}0.015 \\
0.09 \\
0.123 \\
0.132\end{array}$ \\
\hline Waist circumference & $\begin{array}{l}1 \\
2 \\
3 \\
4\end{array}$ & $\begin{array}{l}0.047 \\
-0.004 \\
-0.005 \\
-0.004\end{array}$ & \begin{tabular}{|l|}
0.16 \\
0.888 \\
0.804 \\
0.847
\end{tabular} & $\begin{array}{l}0.001 \\
0.18 \\
0.672 \\
0.675\end{array}$ & $\begin{array}{l}-0.01 \\
0.044 \\
0.023 \\
0.022\end{array}$ & $\begin{array}{l}0.752 \\
0.143 \\
0.224 \\
0.247\end{array}$ & $\begin{array}{l}-0.001 \\
0.181 \\
0.673 \\
0.676 \\
\end{array}$ \\
\hline TG & $\begin{array}{l}1 \\
2 \\
3 \\
4\end{array}$ & $\begin{array}{l}0.053 \\
0.032 \\
0.031 \\
0.042\end{array}$ & $\begin{array}{l}0.108 \\
0.337 \\
0.344 \\
0.174\end{array}$ & $\begin{array}{l}0.002 \\
0.033 \\
0.07 \\
0.168\end{array}$ & $\begin{array}{l}0.008 \\
0.031 \\
0.025 \\
0.015\end{array}$ & $\begin{array}{l}0.82 \\
0.346 \\
0.43 \\
0.628\end{array}$ & $\begin{array}{l}-0.001 \\
0.032 \\
0.07 \\
0.166\end{array}$ \\
\hline HDL-C & $\begin{array}{l}1 \\
2 \\
3 \\
4\end{array}$ & $\begin{array}{l}-0.111 \\
-0.097 \\
-0.095 \\
-0.1\end{array}$ & $\begin{array}{l}{ }^{*} 0.001 \\
{ }^{*} 0.004 \\
{ }^{*} 0.003 \\
{ }^{*} 0.002\end{array}$ & $\begin{array}{l}0.011 \\
0.024 \\
0.078 \\
0.091\end{array}$ & $\begin{array}{l}0.05 \\
0.034 \\
0.041 \\
0.045\end{array}$ & $\begin{array}{l}0.133 \\
0.344 \\
0.205 \\
0.158\end{array}$ & $\begin{array}{l}0.001 \\
0.016 \\
0.072 \\
0.083\end{array}$ \\
\hline FBS & $\begin{array}{l}1 \\
2 \\
3\end{array}$ & $\begin{array}{l}0.05 \\
0.03 \\
0.029\end{array}$ & $\begin{array}{l}0.12 \\
0.371 \\
0.377 \\
\end{array}$ & $\begin{array}{l}0.001 \\
0.029 \\
0.035\end{array}$ & $\begin{array}{l}0.045 \\
0.069 \\
0.066\end{array}$ & $\begin{array}{l}0.172 \\
{ }^{*} 0.037 \\
0.044 \\
\end{array}$ & $\begin{array}{l}0.001 \\
0.033 \\
0.039 \\
\end{array}$ \\
\hline Systolic BP & $\begin{array}{l}1 \\
2 \\
3 \\
4\end{array}$ & $\begin{array}{l}0.062 \\
0.028 \\
0.028 \\
0.031\end{array}$ & $\begin{array}{l}0.063 \\
0.374 \\
0.368 \\
0.326\end{array}$ & $\begin{array}{l}0.003 \\
0.078 \\
0.106 \\
0.114\end{array}$ & \begin{tabular}{|l|}
-0.002 \\
0.035 \\
0.03 \\
0.022 \\
\end{tabular} & \begin{tabular}{|l|}
0.987 \\
0.28 \\
0.35 \\
0.489
\end{tabular} & $\begin{array}{l}-0.001 \\
0.079 \\
0.106 \\
0.114 \\
\end{array}$ \\
\hline Diastolic BP & $\begin{array}{l}1 \\
2 \\
3 \\
4\end{array}$ & $\begin{array}{l}0.111 \\
0.086 \\
0.086 \\
0.088\end{array}$ & $\begin{array}{l}{ }^{*} 0.001 \\
{ }^{*} 0.008 \\
{ }^{*} 0.007 \\
{ }^{*} 0.006\end{array}$ & $\begin{array}{l}0.011 \\
0.054 \\
0.08 \\
0.082\end{array}$ & $\begin{array}{l}0.014 \\
0.043 \\
0.038 \\
0.036\end{array}$ & $\begin{array}{l}0.675 \\
0.19 \\
0.24 \\
0.263\end{array}$ & $\begin{array}{l}-0.001 \\
0.049 \\
0.074 \\
0.076\end{array}$ \\
\hline HOMA_IR & $\begin{array}{l}1 \\
2 \\
3\end{array}$ & $\begin{array}{l}-0.028 \\
-0.034 \\
-0.035\end{array}$ & $\begin{array}{l}0.401 \\
0.309 \\
0.286\end{array}$ & $\begin{array}{l}- \\
0.001 \\
0.038\end{array}$ & $\begin{array}{l}0.037 \\
0.044 \\
0.038\end{array}$ & $\begin{array}{l}0.264 \\
0.191 \\
0.246\end{array}$ & $\begin{array}{l}- \\
0.002 \\
0.038\end{array}$ \\
\hline
\end{tabular}

${ }^{*} \mathrm{P}<0.05$ is significant; $\beta$ : standardized regression coefficients; $\mathrm{R}^{2}$ : coefficient of determination. Model 1 , crude; Model 2 , after adjustment for age; Model 3 , after adjustment for age and BMI; Model 4, after adjustment for age, BMI and HOMA-IR

Table 2: Association of thyroid function tests with metabolic parameters. 


\section{Discussion}

In the present population based study of over 900 reproductive aged women, we found no evidence of an association between thyroid status and the prevalence of Mets, but subclinical thyroid dysfunction was related with two components of Mets (low HDL and high TG). In addition, the average estimated total score of Mets in women with $\mathrm{SCH}$ was significantly higher than the euthyroid women. We found that TSH levels were negatively correlated with HDL-C and positively with diastolic blood pressure independently of well-known MetS risk factors (age, BMI, HOMA-IR).

In this study, $21.2 \%$ of women had subclinical thyroid dysfunction. It is estimated that about $2-20 \%$ people in the world are suffering from $\mathrm{SCH}$ and its prevalence is influenced by the geographic location, sex, diet and race [23]. The prevalence of hypothyroidism in Turkey (16.4\%), United States of America (5.9\%) and Finland (9.5\%) are less than the estimated prevalence in the present study $[19,24,25]$ and our prevalence is similar to the $21.9 \%$ reported by Shantha in India [26].

In the present study, $16.9 \%$ of euthyroid women had Mets that was similar to its prevalence among women with SCH (19.2\%). The prevalence of Mets in our study was less than that reported in the Tehran Lipid and Glucose Study (25\%) [6] which may be explained by their excluding postmenopausal and ageing women. Similar to the our study, the prevalence of Mets in Turkish women with $\mathrm{SCH}$ was similar to the healthy euthyroid women (35\% compared to $33 \%$ ) [26]; furthermore Garcia et al reported that there was no association between Mets or its components and subclinical thyroid dysfunction [24]; despite these findings, Uzunlulu et al observed that the Mets in women with SCH is about three times higher than in healthy women (16.4\% compared with 5.8\%) [19].

Studies have shown that acute administration of TSH to euthyroid subjects caused endothelial dysfunction and increased serum levels of C-reactive protein, TNF- $\alpha$, several indices of oxidative stress and IL-6 $[27,28]$. In the present study, despite no difference in the prevalence of Mets, we found a statistically significant difference in the average total scores of Mets between women with $\mathrm{SCH}$ and euthyroid women $(\mathrm{p}=0.006)$. Moreover, TSH levels were positively correlated with triglycerides and negatively with HDL-C, which may confirm that TSH levels may have long-term harmful effects on cardiovascular health through the association with serum lipids. It has been shown that as a result of decline in the number hepatocytes cell-surface receptors for LDL, resulting in reduced LDL catabolism in women with overt hypothyroidism leads to increased levels of cholesterol and LDL-C and reductions in HDL-C $[29,30]$. However, the results of population studies about the correlation between thyroid function and lipid profiles are controversial [10,31].

In this study there is a negatively significant association between TSH and HDL-C, an association that exists even after adjustment with BMI, age and HOMA-IR. A negative association between HOMA-IR and TSH was reported by Roos et al [8]. However some studies have shown that the association between TSH and serum lipids in women with normal thyroid function is regulated via insulin sensitivity [14]. Similar to our results, Lie et al found no difference in serum insulin levels and HOMA-IR of hypothyroid women in comparison to euthyroid ones [10]; however these levels of insulin in Kuwaiti women with SCH were higher than women with normal thyroid function, despite no discrepancy in their HOMA-IR, [32].

In our study, similar to the Virta study the prevalence of obesity/ overweight in women with subclinical hypothyroid was higher than in euthyroid women [25] whereas Manji reported no correlation between thyroid function status and body mass index in subjects without overt thyroid dysfunction $[18,20]$. It has been shown that in adipocytes and pre adipocytes expressed TSH receptors, TSH binds with its receptors and induces pre adipocytes to produce and release adipokines [33], a mechanism which may explain the correlation between TSH levels and obesity.

There was no consensus regarding the association between increasing systolic or diastolic blood pressures and TSH serum concentrations in women, without overt thyroid dysfunction $[8,34,35]$. In the present study, there was a statistically significant difference between the means of systolic and diastolic blood pressure of women with sub clinical hypothyroidism in comparison to euthyroid participants; however it was not clinically important and the prevalence of hypertension or high blood pressure, as a component of metabolic syndrome, was similar among our study groups. In contrast to the study conducted among Chinese women [10], we observed a positive significant correlation between serum level of TSH and diastolic blood pressure, a correlation that remained after further adjustment for age, BMI and HOMA-IR.

This large community-based study provided us with a unique opportunity to study the association between TSH and the Mets components in an ethnically homogenous population of reproductive aged women. As reported by Janghorbani et al, following a large national survey [36], the educational status and the prevalence of obesity in the present study could justify and confirm our population as being representative of Iranian reproductive aged women [36]. Also the amount of intra-assay variability in our data is likely to be minimal because all laboratory measurements were done at the same laboratory, by the same person. This study does have some limitations. First, its cross-sectional design allowed us to assess only the association rather than causal relationship. Second, since the study population included only Iranian reproductive aged women, results are not applicable to other races, men, post menopausal women or other countries with different iodine intakes.

\section{Conclusion}

In conclusion we found no evidence of an association between thyroid status and Mets, but TSH levels were associated with Mets components, independent of the well-known risk factors of this syndrome. Further investigations are needed to determine the comprehensive mechanism of this correlation.

\section{Acknowledgments}

We are indebted to each of the study participants for the substantial time and effort contributed to this study. The authors also thank the National Counci of Scientific Research of the I.R.Iran for approval and funding of this project as a national research project. We would like to acknowledge Ms Nilufar Shiva for language editing of this manuscript.

\section{Details of Ethics Approval}

The ethical review board of the Research Institute for Endocrine Sciences has approved the study proposal and informed consent was obtained from all subjects.

\section{Funding}

Funded by the National Council of Scientific Research of the I.R.Iran as a national research project.

\section{References}

1. De Flines J, Scheen AJ (2010) Management of metabolic syndrome and associated cardiovascular risk factors. Acta Gastroenterol Belg 73: 261-266. 
Citation: Tehrani FR, Tohidi M, Dovom MR, Azizi F (2011) A Population Based Study on the Association of Thyroid Status with Components of the Metabolic Syndrome. J Diabetes Metab 2:156. doi:10.4172/2155-6156.1000156

2. Caccamo G, Bonura F, Bonura F, Vitale G, Novo G, et al. (2010) Insulin resistance and acute coronary syndrome. Atherosclerosis 211: 672-675.

3. Arsenault BJ, Lemieux I, Després JP, Wareham NJ, Kastelein JJ, et al. (2010) The hypertriglyceridemic-waist phenotype and the risk of coronary artery disease: results from the EPIC-Norfolk prospective population study. Cmaj 182: 1427-1432.

4. Ford ES, Giles WH, Dietz WH (2002) Prevalence of the metabolic syndrome among US adults: findings from the third National Health and Nutrition Examination Survey. Jama 287: 356-359.

5. Soewondo P, Purnamasari D, Oemardi M, Waspadji S, Soegondo S (2010) Prevalence of metabolic syndrome using NCEP/ATP III criteria in Jakarta, Indonesia: the Jakarta primary non-communicable disease risk factors surveillance 2006. Acta Med Indones 42: 199-203.

6. Azizi F, Salehi P, Etemadi A, Zahedi-Asl S (2003) Prevalence of metabolic syndrome in an urban population: Tehran Lipid and Glucose Study. Diabetes Res Clin Pract 61: 29-37.

7. Baskin HJ, Cobin RH, Duick DS, Gharib H, Guttler RB, et al. (2002) American Association of Clinical Endocrinologist Medical guidelines for clinical practice for evaluation and treatment of hyperthyroidism and hyperthyroidism. Endocr Pract 8: 457-469.

8. Roos A, Bakker SJ, Links TP, Gans RO, Wolffenbuttel BH (2007) Thyroid function is associated with components of the metabolic syndrome in euthyroid subjects. J Clin Endocrinol Metab 92: 491-496.

9. Garduno-Garcia Jde J, Alvirde-Garcia U, López-Carrasco G, Padilla Mendoza ME, Mehta R, et al. (2010) TSH and free thyroxine concentrations are associated with differing metabolic markers in euthyroid subjects. Eur $\mathrm{J}$ Endocrinol 163: 273-278.

10. Lai Y, Wang J, Jiang F, Wang B, Chen Y, et al. (2011) The relationship between serum thyrotropin and components of metabolic syndrome. Endocr J 58: 23-30.

11. Mayer O Jr, Simon J, Filipovský J, Plásková M, Pikner R (2006) Hypothyroidism in coronary heart disease and its relation to selected risk factors. Vasc Health Risk Manag 2: 499-506.

12. Feld S, Dickey RA (2001) An Association Between Varying Degrees of Hypothyroidism and Hypercholesterolemia in Women: The Thyroid-Cholesterol Connection. Prev Cardiol 4: 179-182.

13. Danzi S, Klein I (2004) Thyroid hormone and the cardiovascular system. Minerva Endocrinol 29: 139-50.

14. Chubb SA, Davis WA, Davis TM (2005) Interactions among thyroid function, insulin sensitivity, and serum lipid concentrations: the Fremantle diabetes study. J Clin Endocrinol Metab 90: 5317-5320.

15. al-Adsani H, Hoffer LJ, Silva JE (1997) Resting energy expenditure is sensitive to small dose changes in patients on chronic thyroid hormone replacement. J Clin Endocrinol Metab 82: 1118-1125.

16. Beom Jun K, KimT Y, Koh JM, Kim HK, Park JY, et al. (2009) Relationship between serum free T4(FT4) levels and metabolic syndrome (MS) and its components in healty euthyroid subjects. Clinical Endocrinology 70: 152-160.

17. Mohan V, Deepa M, Farooq S, Datta M, Deepa R (2007) Prevalence, awareness and control of hypertension in Chennai--The Chennai Urban Rura Epidemiology Study (CURES-52). J Assoc Physicians India 55: 326-332.

18. Park HT, Cho GJ, Ahn KH, Shin JH, Hong SC, et al. (2009) Thyroid stimulating hormone is associated with metabolic syndrome in euthyroid postmenopausa women. Maturitas 62: 301-305

19. Uzunlulu M, Yorulmaz E, Oguz A (2007) Prevalence of subclinical hypothyroidism in patients with metabolic syndrome. Endocr J 54: 71-76.

20. Manji N, Boelaert K, Sheppard MC, Holder RL, Gough SC, et al. (2006) Lack of association between serum TSH or free T4 and body mass index in euthyroid subjects. Clin Endocrinol (Oxf) 64: 125-128.

21. Grundy SM, Cleeman I, Daniels SR, Donato KA, Eckel RH, et al. (2005) Diagnosis and management of the metabolic syndrome: an American Heart Association/National Heart, Lung, and Blood Institute scientific statement: Executive Summary. Crit Pathw Cardiol 4: 198-203.

22. Delavari A, Forouzanfar MH, Alikhani S, Sharifian A, Kelishadi R (2009) First nationwide study of the prevalence of the metabolic syndrome and optimal cutoff points of waist circumference in the Middle East: the national survey of risk factors for noncommunicable diseases of Iran. Diabetes Care 32: 10921097.

23. Surks MI, Ortiz E, Daniels GH, Sawin CT, Col NF, et al. (2004) Subclinica thyroid disease: scientific review and guidelines for diagnosis and management Jama 291: 228-238.

24. Canaris GJ, Manowitz NR, Mayor G, Ridgway EC (2000) The Colorado thyroid disease prevalence study. Arch Intern Med 160: 526-534.

25. Virta LJ, Eskelinen SI (2011) Prevalence of hypothyroidism in Finland--a nationwide prescription study. Eur J Clin Pharmacol 67: 73-77.

26. Shantha GP, Kumar AA, Jeyachandran V, Rajamanickam D, Rajkumar K, et al (2009) Association between primary hypothyroidism and metabolic syndrome and the role of $C$ reactive protein: a cross-sectional study from South India. Thyroid Res 2: 2.

27. Dardano A, Ghiadoni L, Plantinga Y, Caraccio N, Bemi A, et al. (2006) Recombinant human thyrotropin reduces endothelium-dependent vasodilation in patients monitored for differentiated thyroid carcinoma. J Clin Endocrino Metab 91: 4175-4178.

28. Antunes TT, Gagnon A, Chen B, Pacini F, Smith TJ, et al. (2006) Interleukin-6 release from human abdominal adipose cells is regulated by thyroid-stimulating hormone: effect of adipocyte differentiation and anatomic depot. Am J Physio Endocrinol Metab, 290: 1140-1144.

29. Jung $\mathrm{CH}$, Sung KC, Shin HS, Rhee EJ, Lee WY, et al. (2003) Thyroid dysfunction and their relation to cardiovascular risk factors such as lipid profile hsCRP, and waist hip ratio in Korea. Korean J Intern Med 18: 146-1453.

30. Engler H, Riesen WF (1993) Effect of thyroid function on concentrations of lipoprotein(a). Clin Chem 39: 2466-2469.

31. Takashima N, Niwa Y, Mannami T, Tomoike H, Iwai N (2007) Characterization of subclinical thyroid dysfunction from cardiovascular and metabolic viewpoints: the Suita study. Circ J 71: 191-195

32. Al Sayed A, Al Ali N, Bo Abbas Y, Alfadhli E (2006) Subclinical hypothyroidism is associated with early insulin resistance in Kuwaiti women. Endocr J 53: 653657.

33. Bastemir M, Akin F, Alkis E, Kaptanoglu B (2007) Obesity is associated with increased serum TSH level, independent of thyroid function. Swiss Med Wkly 137: 431-434.

34. Waterhouse DF, McLaughlin AM, Walsh CD, Sheehan F, O'Shea D (2007) An examination of the relationship between normal range thyrotropin and cardiovascular risk parameters: a study in healthy women. Thyroid 17: 243248.

35. Saltiki K, Voidonikola P, Stamatelopoulos K, Mantzou E, Papamichael C, et al (2008) Association of thyroid function with arterial pressure in normotensive and hypertensive euthyroid individuals: A cross-sectional study. Thyroid Res 1 :

36. Janghorbani M, Amini M, Willett WC, Mehdi Gouya M, Delavari A, et al (2007) First nationwide survey of prevalence of overweight, underweight, and abdominal obesity in Iranian adults. Obesity (Silver Spring) 15: 2797-2808. 